\title{
Impact of Nitrogen Fertilization on Chlorophyll Content and Yield of Barley Cultivars Assessed by Fluorescence-Based Approaches
}

Canadian Journal of Agriculture and Crops

Vol. 5, No. 2, 138-152, 2020

e-ISSN: 2518-6655

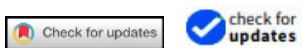

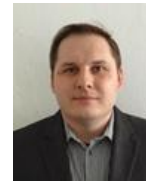

(2) Corresponding Author)

\author{
F. A. Hamann ${ }^{10}$ \\ A. Fiebig ${ }^{2}$ \\ G. Noga ${ }^{3}$
}

1,2,s Department of Horticultural Sciences, Institute of Crop Science and Resource
Conservation, University of Bonn, Germany.
${ }^{2}$ Email:hamann_ufsm@hotmail.com Tel: +49 15208471038
${ }^{2}$ Email: antjefiebig2s@gmail.com Tel: $+49(0) 228-734807$
${ }^{3}$ Email: g:noga@uni-bonn.deTel: $+49(0) 228-735135$

\section{ABSTRACT}

Nitrogen $(\mathrm{N})$ is one of the most important nutrients in crop production to ensure optimal yields. Determining leaf chlorophyll concentration can be a useful indicator of crop nitrogen status and production potential; nevertheless, it is costly, time-consuming and non-practicable when done with traditional wet-chemically methods. Instead, plant fluorescence approaches offer a rapid and nondestructive possibility to instantly assess chlorophyll, nitrogen as well as leaf surface phenolic compounds status. In this study, fluorescence-based sensors were employed to portrait plant physiological conditions and prognosticate yield performance of four different cultivars of summer barley ('Beatrix', 'Eunova', 'Sebastiana', and 'Victoriana') in response to three levels of nitrogen fertilization $(0,40$, and $80 \mathrm{~kg} / \mathrm{ha}$ ). In addition, these indices were contrasted with chlorophyll measured quantitatively by spectrophotometry. Highest chlorophyll content (110 days after sowing, DAS) and grain yield (142 DAS) were observed in all cultivars when $80 \mathrm{~kg} / \mathrm{ha} \mathrm{N}$ was applied. Grain yield strongly correlated with leaf chlorophyll concentration $\left(\mathrm{R}^{2}=0.7, \mathrm{n}=12\right)$, while estimated yield and chlorophyll content using fluorescence indices showed low to moderate correlations. Furthermore, indices estimating flavonol and nitrogen status were less precise, regarding correlations with final yield. Hence, further studies should concentrate on more cultivars and should also consider better adapted fluorescence indices and approaches to estimate plant physiological status in a non-destructive way during growing and pre-generative periods of barley.

Keywords: Simple fluorescence Ratio, Nitrogen balance index, Flavonol index, Grain yield, Fluorescence sensors, Summer barley, Chlorophyll content, Phenolic compounds.

DOI: $10.20448 / 803.5 .2 .138 .152$

Citation | F. A. Hamann; A. Fiebig; G. Noga (2020). Impact of Nitrogen Fertilization on Chlorophyll Content and Yield of Barley Cultivars Assessed by Fluorescence-Based Approaches. Canadian Journal of Agriculture and Crops, 5(2): 138-152.

Copyright: This work is licensed under a Creative Commons Attribution 3.0 License

Funding: This study was part of the CROPSENSE.net research project "Networks of excellence in agricultural and nutrition research", which was financially supported by the German Federal Ministry of Education and Research (BMBF 0315529) and the European Union for regional development (z1011bc001a). Authors thank the sponsors for financial and scientific support.

Competing Interests: The authors declare that they have no competing interests.

History: Received: 28 April 2020/ Revised: 3 June 2020/ Accepted: 7 July 2020/ Published: 30 July 2020

Publisher: Online Science Publishing 


\section{Highlights of this paper}

- This study examinated the application of agricultural non-destructive sensors in the field to cover crop physiological responses of summer barley to the supply of different nitrogen fertilization levels, comparing with referential parameters such as chlorophyll content and grain yield.

- Grain yiled strongly correlated with leaf chlorophyll content.

- Fluorescence indices related to chlorphyll content showed moderate correlations.

\section{INTRODUCTION}

Nitrogen $(\mathrm{N})$ is one of the most important chemical elements in plant nutrition, playing a major role in achieving higher crop productivity and yield [1,2]. Biochemically, it can be combined as amine (-NH2) with other elements, i.e. carboxyl (-COOH) functional groups and a specific side chain ( $\mathrm{R}$ group), to be assimilated into essential amino acids [3], which are necessary for forming proteins to trigger plant's growth and development [4]. Moreover, in chloroplasts, $\mathrm{N}$ atoms bind to the atom of magnesium $(\mathrm{Mg})$, constituting a structural integrant of the chlorophyll molecule, which is the vital pigment for plants to absorb light energy and set off light-dependent reactions during photosynthesis [5].

Nitrogen is considered a key plant fertilizer extensively applied in crop systems. However, its shortage can lead to impairment of leaf elongation by lowering turgor and/or cell wall extensibility and ultimately greatly reduce yield and quality of crops [6]. In contrast, $\mathrm{N}$ excess stimulates growth of foliage, surpassing flowering, fruiting and/or formation of storage organs such as tubers and roots [7-9]. Excessive nitrogen fertilization often leads to a reduction in net returns and groundwater contamination through nitrate (NO3-N) leaching, denitrification, and volatilization, what is not in lines with sustainable agricultural practices. Because of its mobility in the soil system, it can be found in many forms and it can easily change from one to the other [10]. Due to this feature, it is well known that this nutrient needs to be replaced whenever it is removed (for example when the crop is harvested), in order that soil's nutritional balance can be maintained [11]. Therefore, a balance between supply and utilization of nitrogen is necessary, not only to optimize crop growth and economic returns, but also to minimize negative environmental impacts.

When important decisions on crop nutritional management are needed, non-destructive methods to assess crop nitrogen status qualitatively appear as a convenient and practical way to evaluate both plant's physiological condition and nutritional requirements in vegetative and pre-generative stages. Amongst several procedures offered currently in precision farming, the employment of portable sensors based on chlorophyll fluorescence (ChlF) seems to be a promising technique to be applied in crop fields. The principle of ChlF is based on the fluorescence emission of the chlorophyll a molecule, detected in the red (R) (F680) and far-red (FR) (F730) spectral regions [12, 13]. In commercial sensors, fluorescence emissions are induced by the incidence of shorter wavelength electromagnetic signals emitted in the light spectrum, comprehending the region between ultraviolet (UV) and R [14-16]. The red fluorescence light is selectively reabsorbed by chlorophyll, whereas the near-infrared fluorescence light is only slightly affected [17]. The degree of reabsorption is strongly dependent on the chlorophyll concentration [18], hence measuring the intensity of R and FR fluorescence light provides information about the chlorophyll content [14].

In addition, the natural occurrence of phenolic compounds in the leaf epidermis, especially flavonols (Flav), can be detected in the UV-A spectral region. Furthermore, the qualitative ratio of chlorophyll to flavonols (Chl/Flav) can serve as basis to estimate the balance of nitrogen level in leaves, resulting in a new index called nitrogen balance index (NBI) [16, 19, 20]. Unlike the traditional methods, such as transmission and reflectance measurements, chlorophyll fluorescence, although having a relatively weaker detected signal, has the advantage of 
being plant specific by characterizing photosynthetic activity [21] and exhibiting greater sensitivity, since fluorescence signals only come from the plant [22].

Considering the cultivation of barley (Hordeum vulgare L.), fluorescence sensor techniques have been employed to some extent to understand the impact of constraining growing conditions on the photosynthetic apparatus. Yu, et al. [23] performed the detection of fluorescence by using a portable sensor with light emitting diodes, demonstrating that non-invasive spectral measurements are able to detect mild disease symptoms before significant losses in leaf chlorophyll content appeared in field conditions. In turn, Kalaji and Guo [24] applied variable ChlF, also called Kautsky kinetics technique [13], verifying that different ChlF parameters can be used as trustworthy indicators during selection processes of stress tolerant genotypes. In addition, imaging of fast chlorophyll fluorescence induction curve (OIJP) parameters proved to be suitable in screening and phenotyping studies on barley genotypic characterization [25]. Yet, there is only limited information concerning the employment of fluorescence-based sensors without leaf dark adaption to assess $\mathrm{N}$ fertilization impacts under field conditions. In light of this, the purpose of this study was to verify whether fluorescence sensors can be a helpful non-destructive methodology to early estimate chlorophyll content and the final yield of four barley cultivars subjected to different nitrogen fertilization levels under field conditions. This study also compares indices from three different sensors to understand whether they display similar trends.

\section{MATERIAL AND METHODS}

\subsection{Plant Material, Growth Conditions And Experimental Set-Up}

The experiment was conducted from May to July 2014 at the experimental fields of the Agricultural Faculty at the South-Westphalia University of Applied Sciences, Iserlohn, Germany $\left(51^{\circ} 22^{\prime} 5.52^{\prime \prime} \mathrm{N}, 7^{\circ} 41^{\prime} 12.48^{\prime \prime} \mathrm{E}\right)$. The predominant soil in this region is stagnosol with the main compound being mid clay silt (80-85\%) and a humus content below $2.0 \%$. During the vegetation period, daily temperatures varied from 11.5 to $22{ }^{\circ} \mathrm{C}$ and relative air humidity from 52 to $96 \%$. The research area (approximately 0.2 ha) consisted of 96 randomized plots, each of 8.75 $\mathrm{m}^{2}$ in size. Before the experiment was performed, maize (Zea mays L.) was grown and the residues were incorporated into the soil after corn harvest. Soil analysis taking subsamples was performed for the whole area. Determined mean values for NPK, $\mathrm{Mg}$ and $\mathrm{pH}$ were as follows: $\mathrm{Nmin}=52 \mathrm{~kg} / \mathrm{ha}, \mathrm{P} 2 \mathrm{O} 2=19 \mathrm{mg} / 100 \mathrm{~g}, \mathrm{~K} 2 \mathrm{O}=13 \mathrm{mg} / 100 \mathrm{~g}, \mathrm{MgO}$ $=6 \mathrm{mg} / 100 \mathrm{~g}, \mathrm{pH}=6.3$

For the field experiment, two factors were chosen:

1. Amount of nitrogen application (0, 40 and $80 \mathrm{~kg} / \mathrm{ha})$.

2. Barley cultivar ('Beatrix', 'Eunova', 'Sebastiana' and 'Victoriana').

Barley seeds, obtained from CropSense.net* seedbank, were sown into completely randomized plots with eight replicates for each treatment. The crop was cultivated according to the common practice; however, the nitrogen application was altered in the following way: Nitrogen fertilization was given in the form of calcium ammonium nitrate, with $27 \% \mathrm{~N}$ in its formulation, in three different levels (0, 40 and $80 \mathrm{~kg} / \mathrm{ha})$. Nitrogen was applied according to BBCH-scale (German "Biologische Bundesanstalt, Bundessortenamt und Chemische Industrie"; [26, 27] between the stage 14 (leaf development) and 21 (beginning of tillering), while the $80 \mathrm{~kg} / \mathrm{ha}$ treatment group received the remaining portion in a second application between 39 - 49 (booting stage). Plots without N-supply (0 $\mathrm{kg} / \mathrm{ha}$ ) were used as control. Grain harvest was undertaken on August 1st, (142 DAS), which corresponded to the stage BBCH 99 (the harvested product). 


\subsection{Fluorescence Sensors And Indices}

Fluorescence recordings were taken at $65,75,85$ and 110 DAS, corresponding to the BBCH stages in between 37 - 39, 49 - 51, 51 - 59 and 59 - 61, respectively. Three different non-sample destructive and non-sample darkadapted sensors for instant fluorescence assessment were used for the measurements, as presented and described as follows. The handheld sensor Dualex®4 scientific (Force-A, Orsay, France) combines the use of fluorescence and light transmission of a leaf to evaluate physiological and biochemical parameters [16]. It determines the optical absorbance of the leaf epidermis in the ultraviolet (UV) range through the differential measurement of the chlorophyll fluorescence and can also estimate the chlorophyll content of the leaf using different wavelengths in the $\mathrm{R}$ and in the FR region. For each plot and evaluation date, 10 flag leaves were measured and averaged and the following indices reported: Chl (called 'Chl_Index' in this study to avoid misunderstanding with the quantitative leaf chlorophyll content), NBI and Flav (here called Flav_Dx to avoid misunderstanding with Flav_Mx from Multiplex $\left.{ }^{\circledR}\right)$. The portable multiparametric fluorescence sensor Multiplex ${ }^{\circledR}$ (Force-A, Orsay, France) used in this work has been described in previous studies [28-30]. Briefly, light emitting diodes (LED) excite the fluorescence at three high energy excitation channels, i. e. at $375 \mathrm{~nm}$ (UV), $518 \mathrm{~nm}$ (green) and $630 \mathrm{~nm}$ (red), while the plant emitting fluorescence was detected in the red (RF: 680-690 nm) and far-red (FRF: 720-755 nm) spectral regions. A grid was used in front of the optical unit to enable the illumination of an area of approximately $5.10^{-3} \mathrm{~m}^{2}$ by maintaining a constant distance of $0.10 \mathrm{~m}$ between the equipment and the leaf surface. The measurements were taken in each plot, with one measurement in 'one-shot-mode' per plot, and the indices SFR_R, NBI_R, and Flav_Mx were selected to be reported. The fluorescence sensor MiniVeg-N (Fritzmeier Umwelttechnik GmbH, Großheldendorf, Germany) is an active optical sensor using the measuring principle of laser-induced chlorophyll fluorescence (LICF). Core of the device is an internal laser diode (red light laser - R), inducing the chlorophyll molecules in plant cells to emit fluorescence light. The intensity of fluorescence light is detected with highly sensitive optical components at the wavelengths of $690 \mathrm{~nm}$ (red - R; F690) and $730 \mathrm{~nm}$ (far-red - FR; F730) and the vegetation index ratio is calculated (F690/F730) [22]. In this study, the vegetation index ratio was inverted, i.e. F730/F690, to be directly correlated with Chl_Index and SFR_R. In the field, the equipment was mounted onto a pushcart, the way that its two measuring heads, one left- and the other right-sided, attached to a rod, could be driven along the rows between the plots while the fluorescence signals emitted by the leaves could be recorded in continuous mode.

Further information about the indices and their corresponding formula analysed in this study can be found in Table 1.

Table-1. Fluorescence indices recorded by hand-held and implement-mounted sensors used for screening plant physiological status.

\begin{tabular}{|c|c|c|c|}
\hline Index & Sensor & Description & Formula \\
\hline Chl Index & Dualex $^{\circledR}$ & Chlorophyll content estimation & $\mathrm{FRT}_{1}-\mathrm{RT}_{2} / \mathrm{RT}$ \\
\hline SFR_R & Multiplex ${ }^{\circledR}$ & Simple Fluorescence Ratio (red light excitation) & $\mathrm{FRF}_{-} \mathrm{R}_{3} / \mathrm{RF}_{-} \mathrm{R}_{4}$ \\
\hline $\mathrm{F} 730 / \mathrm{F} 690$ & MiniVegN & Chlorophyll estimation ratio & $\mathrm{FRF}_{-} \mathrm{R} / \mathrm{RF}_{-} \mathrm{R}$ \\
\hline NBI & Dualex $^{\circledR}$ & Nitrogen Balance Index & Chl Index/Flav_Dx \\
\hline NBI_R & Multiplex ${ }^{\circledR}$ & Nitrogen Balance Index (red light excitation) & $\mathrm{FRF}_{-} \mathrm{UV}_{5} / \mathrm{RF}_{-} \mathrm{R}$ \\
\hline Flav_Dx & Dualex $^{\circledR}$ & Epidermal flavonol content & $\mathrm{Log}_{\mathrm{FRF}} \mathrm{R}_{\mathrm{R}} / \mathrm{FRF}_{-} \mathrm{UV}$ \\
\hline Flav_Mx & Multiplex ${ }^{\circledR}$ & Epidermal flavonol content & $\log \left(\mathrm{FER}_{-} \mathrm{UV}_{6}\right)$ \\
\hline $\begin{array}{l}\text { Note: }{ }^{1}: \mathrm{FRT}=\text { far } \\
2: \mathrm{RT}=\text { red transm } \\
\text { 3: FRF_R = far-red } \\
\text { 4: RF_R = red fluor } \\
\text { 5: FRF_UV = far-r } \\
\text { 6: FER_UV = fluor }\end{array}$ & $\begin{array}{l}\mathrm{d} \text { transmission. } \\
\text { ion. } \\
\text { lorescence with } \mathrm{r} \\
\text { cence with red ex } \\
\text { fluorescence with }\end{array}$ & $\begin{array}{l}\text { itation light. } \\
\text { on light. } \\
\text { excitation light. } \\
\text { ith red and UV excitation lights. }\end{array}$ & \\
\hline
\end{tabular}




\subsection{Leaf Chlorophyll Concentration}

Chlorophyll concentration was determined wet-chemically at 110 DAS. For this purpose, 20 flag leaves of each plot were collected and cold-transported to the laboratory, immediately frozen $\left(-20{ }^{\circ} \mathrm{C} \pm 2\right)$, freeze-dried, ground and stored in the dark at room temperature $\left(20^{\circ} \mathrm{C} \pm 5\right)$. Chlorophyll concentration was determined colorimetrically according to the method of Holden [31] as well as Strobl and Türk [32]. Briefly, $5 \mathrm{ml}$ of methanol was added to 50 $\mathrm{mg}$ of the dried and ground sample, mixed and centrifuged at $4.000 \mathrm{rpm}$ for $15 \mathrm{~min}$ (Varifuge $3 \mathrm{OR}$, Heraeus Sepatech GmbH, Hanau, Germany). The supernatant was then decanted into $50 \mathrm{ml}$ flasks and the pellet was extracted three more times until the extract was colourless. The collected supernatant was filled up $50 \mathrm{ml}$ with methanol. Absorbance of the extracts was measured with a UV-VIS spectrophotometer (Perkin-Elmer, Lambda 35, Waltham, MA, USA) at $650 \mathrm{~nm}$ and $665 \mathrm{~nm}$. The following equations were used to calculate the concentrations of chlorophyll a (Chl a), chlorophyll b (Chl b) and total chlorophyll $(\mathrm{Chl} \mathrm{a}+\mathrm{b})$ :

$$
\begin{gathered}
\mathrm{Chl} \mathrm{a}=[(16.5 \times \mathrm{A} 665)-(8.3 \times \mathrm{A} 650)] \times \mathrm{Vol} / \mathrm{DM} \text { of sample material } \\
\mathrm{Chl} \mathrm{b}=[(33.8 \times \mathrm{A} 650)-(12.5 \times \mathrm{A} 665)] \times \mathrm{Vol} / \mathrm{DM} \text { of sample material } \\
\mathrm{Chl} \mathrm{a}+\mathrm{b}=[(25.5 \times \mathrm{A} 650)+(4 \times \mathrm{A} 665)] \times \mathrm{Vol} / \mathrm{DM} \text { of sample material }
\end{gathered}
$$

Where:

A650 $=$ absorbance at a wavelength of $650 \mathrm{~nm}$.

A665 = absorbance at a wavelength of $665 \mathrm{~nm}$.

$\mathrm{Vol}=$ volume of the filtrated material.

$\mathrm{DM}=$ dry mass of the sample material.

For data evaluation and statistical proceeds, we focused on the total leaf chlorophyll concentration, indicated in $\mathrm{mg} / \mathrm{g}$ of the sampled DM.

\subsection{Statistical Analysis}

Data was statistically analysed with (SPSS) statistic software (PASW statistics version 23.0, SPSS Inc., Chicago, IL, USA). One-way ANOVA and independent-samples-T-Test for nitrogen fertilization on 65 DAS, as well as a complimentary Duncan post-hoc analysis was used to compare the mean values. The results are expressed as mean \pm standard error (SE), and the level of statistical significance of differences is $p \leq 0.05$. For regression analysis, mean values (of each treatment and fertilization level) of yield and measured fluorescence indices and leaf chlorophyll content were correlated and the coefficient of determination (R2), $\mathrm{p} \leq 0.05$, is given.

\section{RESULTS}

\subsection{Grain Field}

In all cultivars, the highest nitrogen level $(80 \mathrm{~kg} / \mathrm{ha})$ resulted in the highest yield, though no statistically significant difference was seen between the two applied doses (40 and $80 \mathrm{~kg} / \mathrm{ha}$ ), apart from 'Eunova', where 80 $\mathrm{kg} / \mathrm{ha}$ resulted in the significantly highest yield Figure 1. The cultivar 'Beatrix' showed highest yield for all fertilization levels, with 76.4, 73.1, and $62.3 \mathrm{dt} / \mathrm{ha}$ for 80,40 and $\mathrm{o} \mathrm{kg} / \mathrm{ha}$, respectively. In contrast, 'Sebastiana' had the lowest yield, with $70.7,65.8$, and $53.7 \mathrm{dt} /$ ha respectively. 


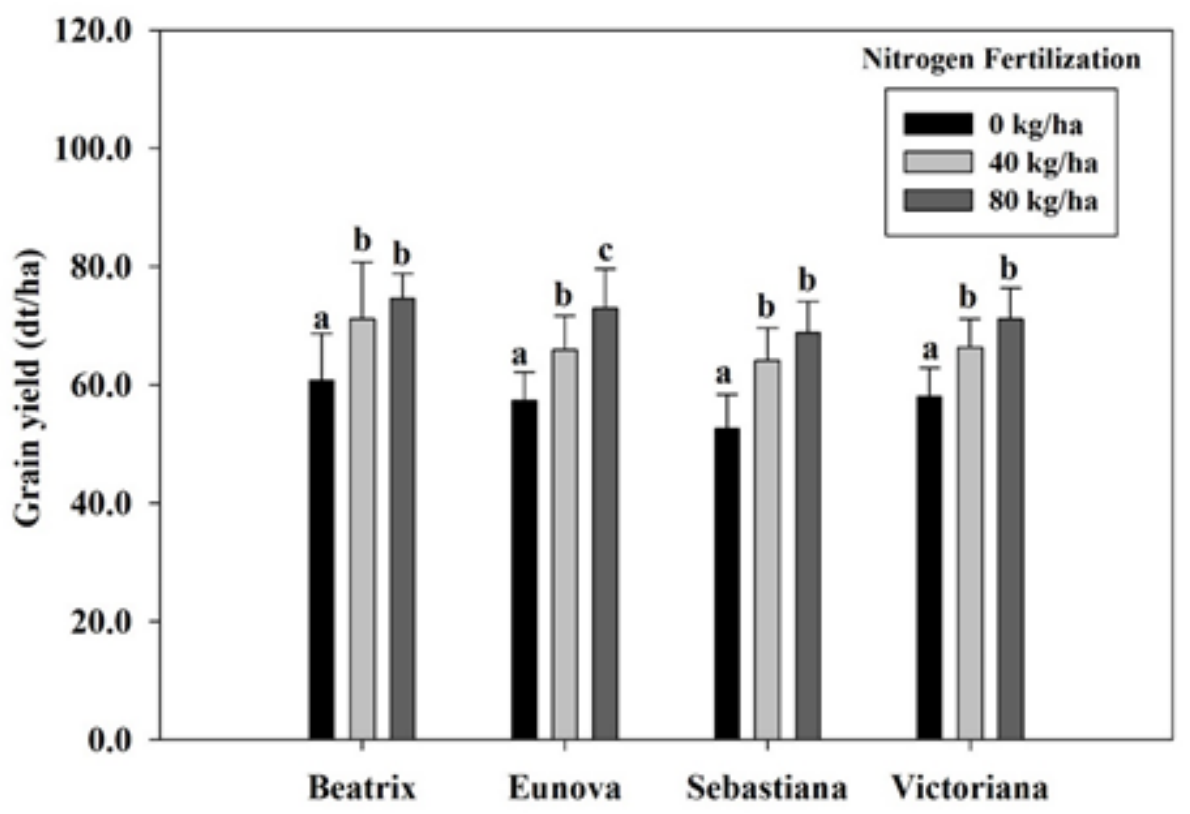

Figure-1. Grain yield (dt/ha) of summer barley cultivar Beatrix, Eunova, Sebastiana and Victoriana fertilized with different nitrogen levels (0 $\mathrm{kg} / \mathrm{ha}=$ black; $40 \mathrm{~kg} / \mathrm{ha}=$ grey; $80 \mathrm{~kg} / \mathrm{ha}=$ dark grey vertical bar $)$. Means $\pm \mathrm{SE}(\mathrm{n}=8$ repetitions $)$ of the same cultivar followed by different letters indicate significant differences between

\subsection{Chlorophyll-Content Fluorescence Indices}

All chlorophyll-content-linked fluorescence indices (Chl Index, SFR_R and F730/F690) showed similar tendencies for all cultivars in response to the different $\mathrm{N}$ fertilization levels Figure 2. There was no significant difference between the 0 and $40 \mathrm{~kg} /$ ha nitrogen treatments on 65 DAS (first measurement day), except for 'Beatrix', where the plants with an applied dose of $40 \mathrm{~kg} / \mathrm{ha}$ displayed a higher SFR_R expression Figure 2. From 75 DAS to 110 DAS, the highest $\mathrm{N}$ fertilization treatment yielded highest indices for all cultivars and evaluated chlorophyll parameters. In general, all four cultivars displayed a decreased tendency for all indices recorded between the end of earing and beginning of blooming (110 DAS) Figure 2.

\subsection{Nitrogen Balance Indices}

Figure 3 displays the effect of $\mathrm{N}$ fertilization on the nitrogen balance indices (NBI and NBI_R). Both parameters showed decreased values subsequent to 75 DAS for all cultivars and fertilization levels, though plots that received $80 \mathrm{~kg} / \mathrm{ha}$ of $\mathrm{N}$ fertilizer continued to express slightly higher values than those that received the other doses. Similar to the chlorophyll indices, nitrogen balance indices were lowest for all cultivars on 110 DAS. Interestingly, the NBI_R showed a sharp decrease from 85 DAS to 110 DAS for all cultivars and also resulted in no significant differences between the three nitrogen treatments at the last measuring date. 

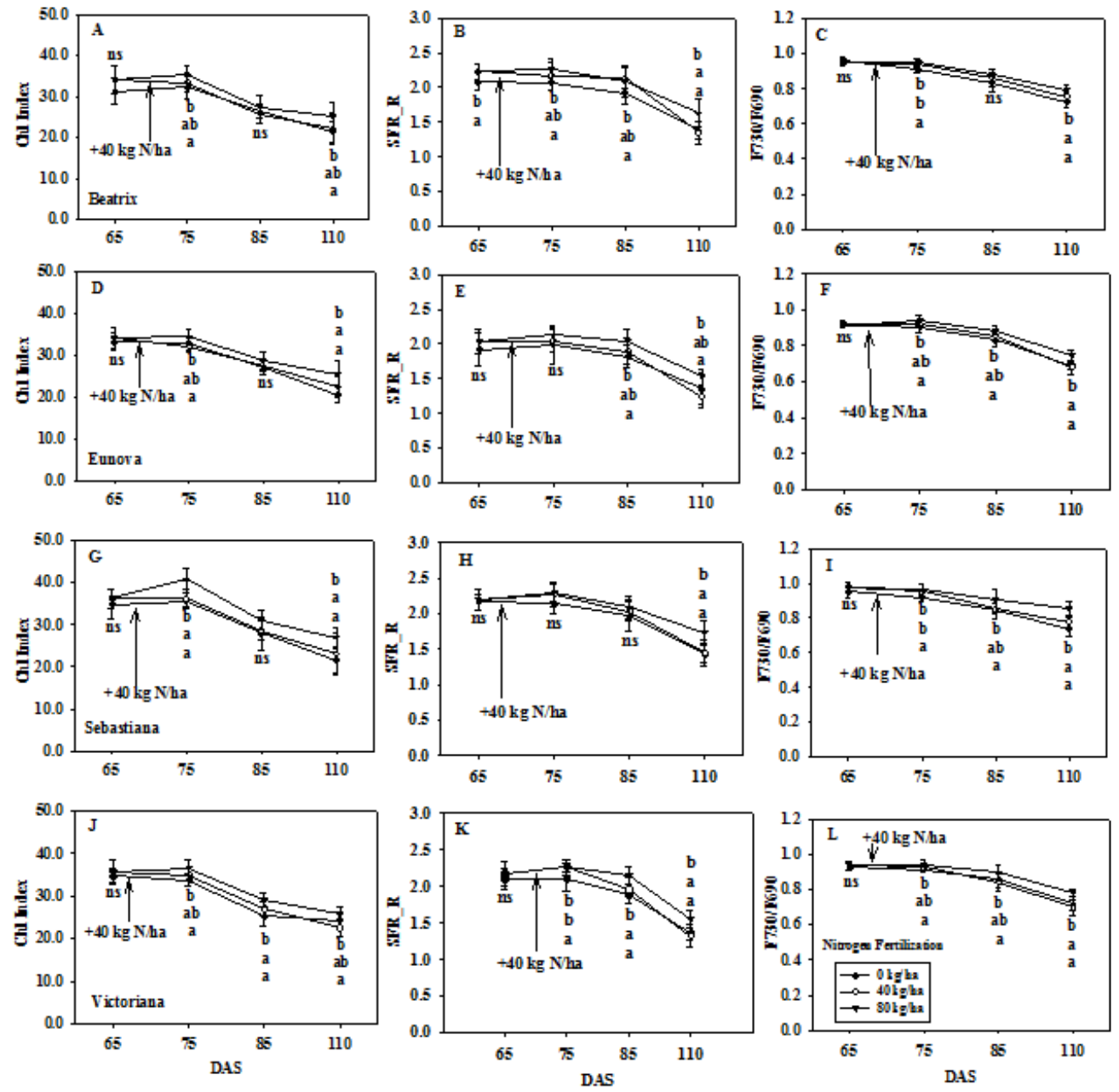

Figure-2. Chlorophyll indices on four evaluation dates (DAS 65, 75, 85 and 110) recorded via Dualex ${ }^{\circledR}$ (Chl Index), Multiplex ${ }^{\circledR}$ (SFR_R) and MiniVeg-N (F 730/F690) of the barley cultivars Beatrix (A, B, C), Eunova, (D, E, F), Sebastiana (G, H, I) and Victoriana (J, K, L) fertilized with different nitrogen levels $(0 \mathrm{~kg} / \mathrm{ha}=$ closed circle; $40 \mathrm{~kg} / \mathrm{ha}=$ open circle; $80 \mathrm{~kg} / \mathrm{ha}=$ closed triangle). Means $\pm \mathrm{SE}(\mathrm{n}=8 \mathrm{repetitions})$ followed by different letters indicate significant differences between treatments, ns indicates no significance (t-test and ANOVA, $p \leq 0.05)$ by Duncan Test.

\subsection{Flavonol Indices}

Figure 4 shows the evolution of fluorescence signals detected by Dualex $\AA$ and Multiplex ${ }^{\circledR}$ from epidermal secondary metabolites belonging to the flavonoid-group, the flavonols. Flav_Dx did not reveal any significant differences between the fertilization treatments for the cultivar 'Sebastiana' on all days measured and 'Victoriana' on 65, 85 and 110 DAS. Even though the other two cultivars showed varying Flav_Dx indices during the recording period depending on the nitrogen regime, there was no significant difference on 110 DAS. Flav_Mx values showed similar time-curves; however, the values between the different nitrogen regimes were more distinguishable.

\subsection{Fluorescence Indices $x$ Cultivars}

In a similar way to the fluorescence signals evaluated for the nitrogen levels, the four cultivars displayed distinct patterns on the evolution of chlorophyll, nitrogen and flavonol fluorescence indices.

Figure 5 presents a decreasing curve for F730/F690, Chl_Index, SFR_R, NBI and NBI_R whilst crop development advances. Although a tendency could not be assumed in all growing phases, the cultivar 'Sebastiana' expressed higher chlorophyll content and nitrogen balance indices Figure 5A-E and lower Flav_Dx on 85 and 110 
DAS Figure 5F. Together with 'Victoriana', 'Sebastiana' showed lower flavonol fluorescence also on 85 and 100 DAS for Flav_Mx Figure 5G. On the other hand, 'Beatrix' and 'Eunova' contrasted with a higher expression of the phenolic index on both evaluated parameters Figure $5 \mathrm{G}-\mathrm{H}$.
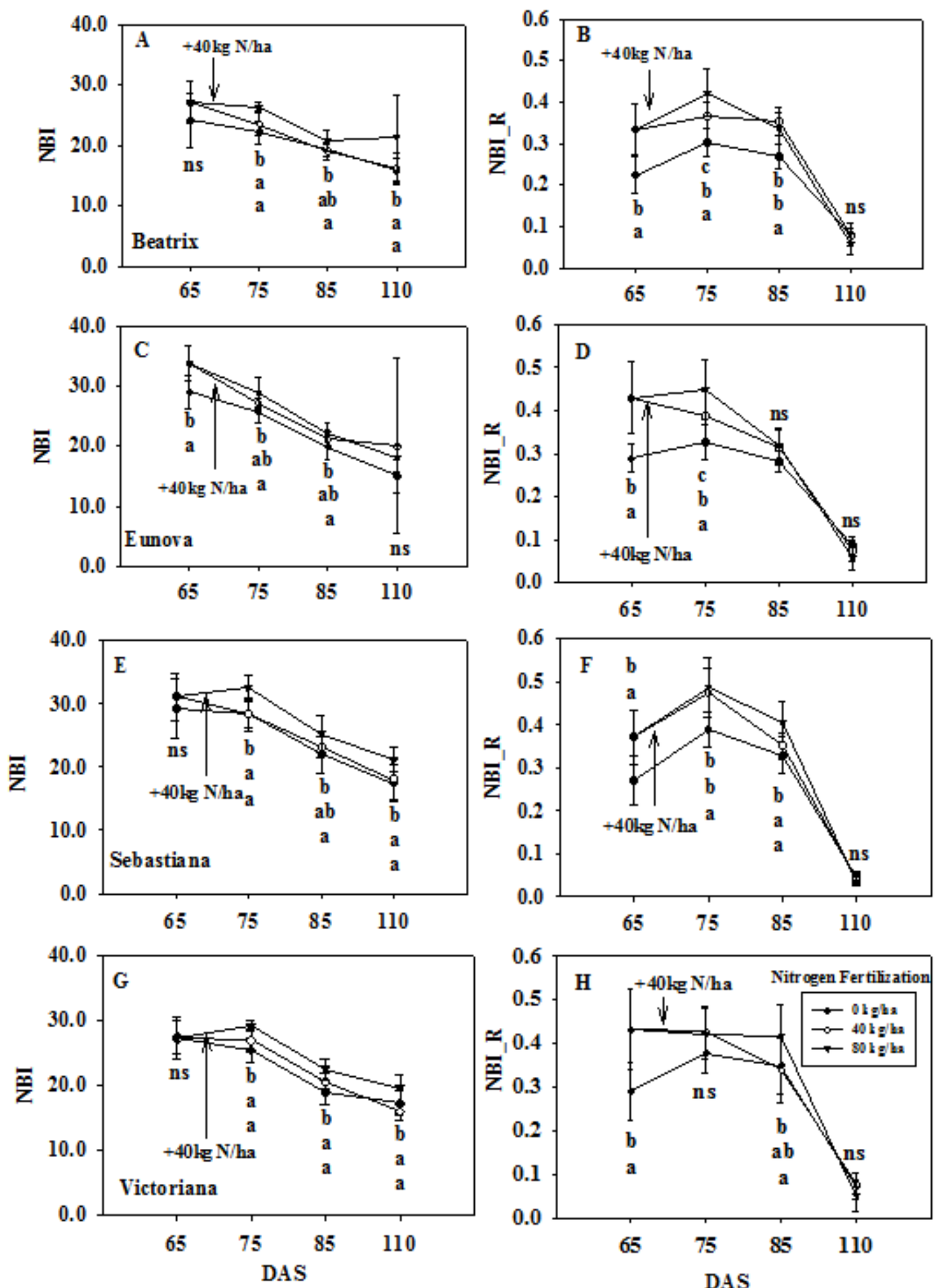

Figure-3 Nitrogen Balance Indices on four evaluation dates (DAS 65, 75, 85 and 110) recorded via Dualex ${ }^{\circledR}$ (NBI) and Multiplex $^{\circledR}$ (NBI_R) of the barley cultivars Beatrix (A, B), Eunova, (C, D), Sebastiana (E, F) and Victoriana (G, H) fertilized with different nitrogen levels $(0 \mathrm{~kg} / \mathrm{ha}=$ closed circle; $40 \mathrm{~kg} / \mathrm{ha}=$ open circle; $80 \mathrm{~kg} / \mathrm{ha}=$ closed triangle). Means $\pm \mathrm{SE}(\mathrm{n}=8$ repetitions) followed by different letters indicate significant differences between treatments, $\mathrm{ns}$ indicates no significance (t-test and ANOVA, $p \leq 0.05$ ) by Duncan Test. 

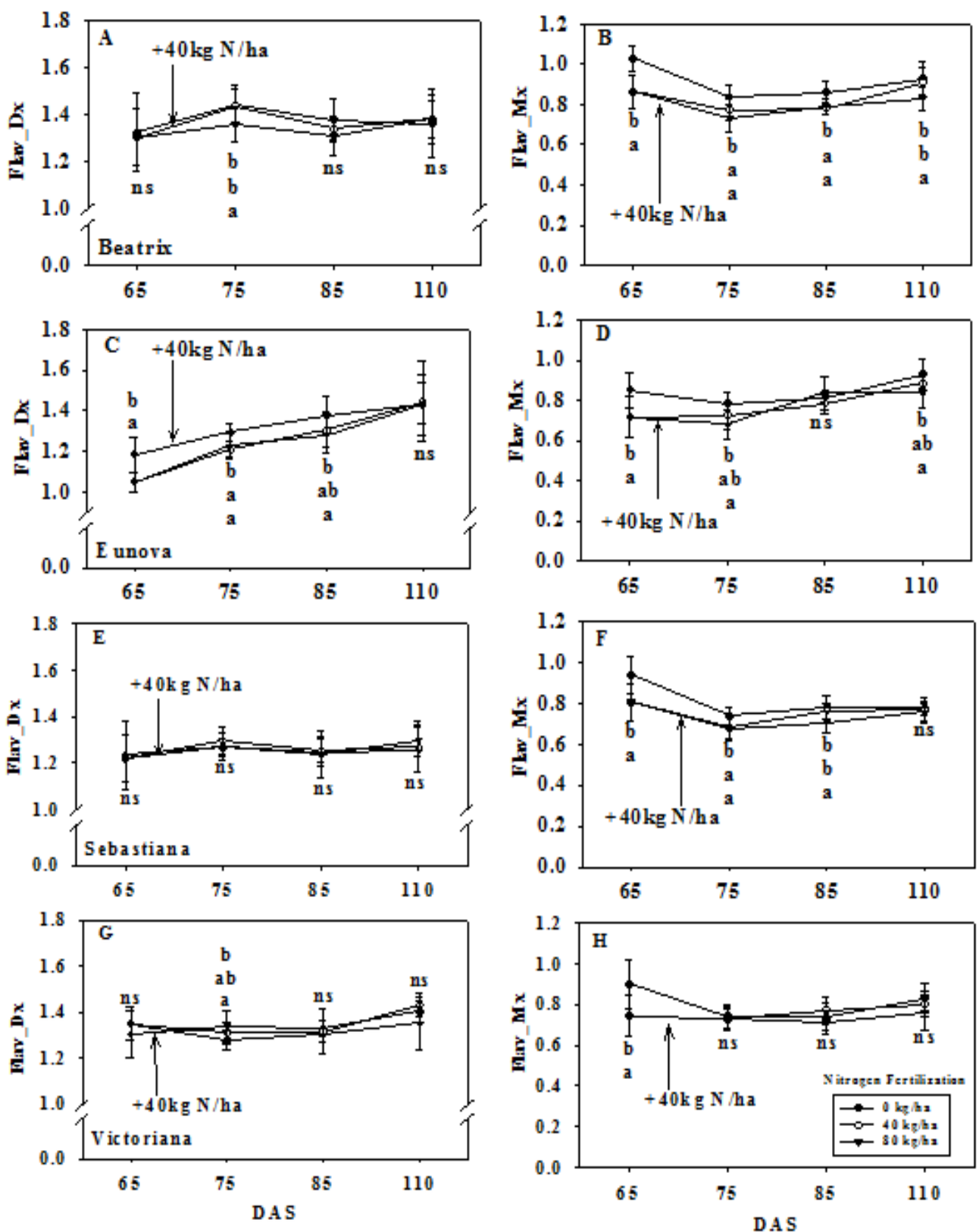

Figure-4. Flavonol indices recorded with the Dualex ${ }^{\circledR}$ (Flav_Dx and Multiplex ${ }^{\circledR}$ Flav_Mx) devices of the barley cultivars Beatrix (A, B), Eunova, (C; D), Sebastiana (E; F) and Victoriana $(G ; H)$ on four evaluation dates (DAS $65,75,85$ and 110$)$ and influenced by nitrogen fertilization levels $(0 \mathrm{~kg} / \mathrm{ha}=$ closed circle; $40 \mathrm{~kg} / \mathrm{ha}=$ open circle; $80 \mathrm{~kg} / \mathrm{ha}=$ closed triangle). Means $\pm \mathrm{SE}(\mathrm{n}=8$ repetitions $)$ followed by different letters indicate significant differences between treatments, ns indicates no significance (t-test and ANOVA, $p \leq 0.05$ ) by Duncan Test.

\subsection{Leaf Chlorophyll Concentration}

The laboratory analysis of chlorophyll content on 110 DAS showed significant differences between N fertilization treatments, with higher concentrations of the photosynthetic pigment for the highest applied dose (80 $\mathrm{kg} / \mathrm{ha}$ ), even though no statistically significance was portrayed between the two applied doses, apart from 'Eunova', where $40 \mathrm{~kg} / \mathrm{ha}$ did not induce higher chlorophyll accumulation Figure 6. There was no significant difference between the evaluated cultivars. 

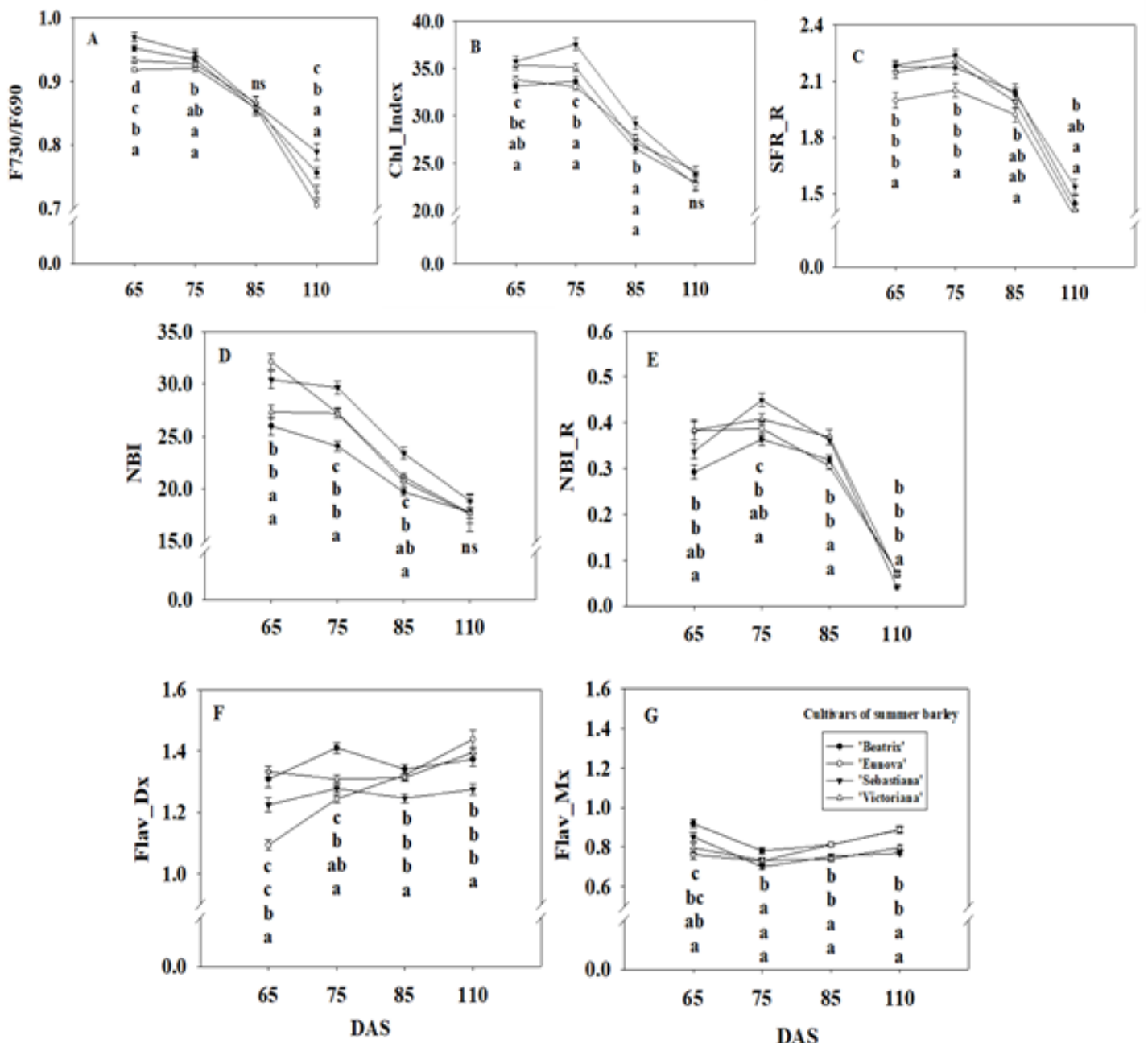

Figure-5. Chlorophyll, nitrogen and flavonol indices on four evaluation dates (DAS 65, 75, 85 and 110) recorded via MiniVeg-N $(\mathrm{A}=\mathrm{F} 730 / \mathrm{F} 690)$, Dualex ${ }^{\circledR}(\mathrm{B}=\mathrm{Chl}$ Index, $\mathrm{D}=\mathrm{NBI}$ and $\mathrm{F}=$ Flav_Dx $)$ and Multiplex ${ }^{\circledR}(\mathrm{C}=\mathrm{SFR} \mathrm{R}$ and $\mathrm{E}=\mathrm{NBI} \mathrm{R})$ of the barley cultivars Beatrix $=$ close circle, Eunova $=$ open circle, Sebastiana $=$ close triangle, and Victoriana $=$ open triangle. Means $\pm \mathrm{SE}(\mathrm{n}=8$ repetitions) followed by different letters indicate significant differences between treatments, ns indicates no significance (ANOVA, $p \leq 0.05$ ) by Duncan Test.

\subsection{Linear Model Between Chlorophyll Content and Grain Yield}

Final grain yield (142 DAS) and leaf chlorophyll content (110 DAS) strongly correlated $(\mathrm{R} 2=0.7)$ Figure 7 . In contrast, only low correlations were seen between chlorophyll indices and grain yield for different measuring days: F730/F690 on 75 and 85 DAS (R2 = 0.53), SFR_R on 85 DAS $(\mathrm{R} 2=0.55)$, and Chl Index on 110 DAS $(\mathrm{R} 2=0.43)$. In addition, neither flavonol indices (Flav_Dx and Flav_Mx) nor nitrogen balance indices (NBI and NBI_R) from any measuring day showed significant correlation with the final grain yield Table 2 .

In the Results section, summarize the collected data and the analysis performed on those data relevant to the discourse that is to follow. Report the data in sufficient detail to justify your conclusions. Mention all relevant results, including those that run counter to expectation; be sure to include small effect sizes (or statistically nonsignificant findings) when theory predicts large (or statistically significant) ones. Do not hide uncomfortable results by omission. Do not include individual scores or raw data with the exception, for example, of single-case designs or illustrative examples. In the spirit of data sharing (encouraged by APA and other professional associations and sometimes required by funding agencies), raw data, including study characteristics and indivldual effect sizes used in a meta -analysis, can be made available on supplemental online archives. 

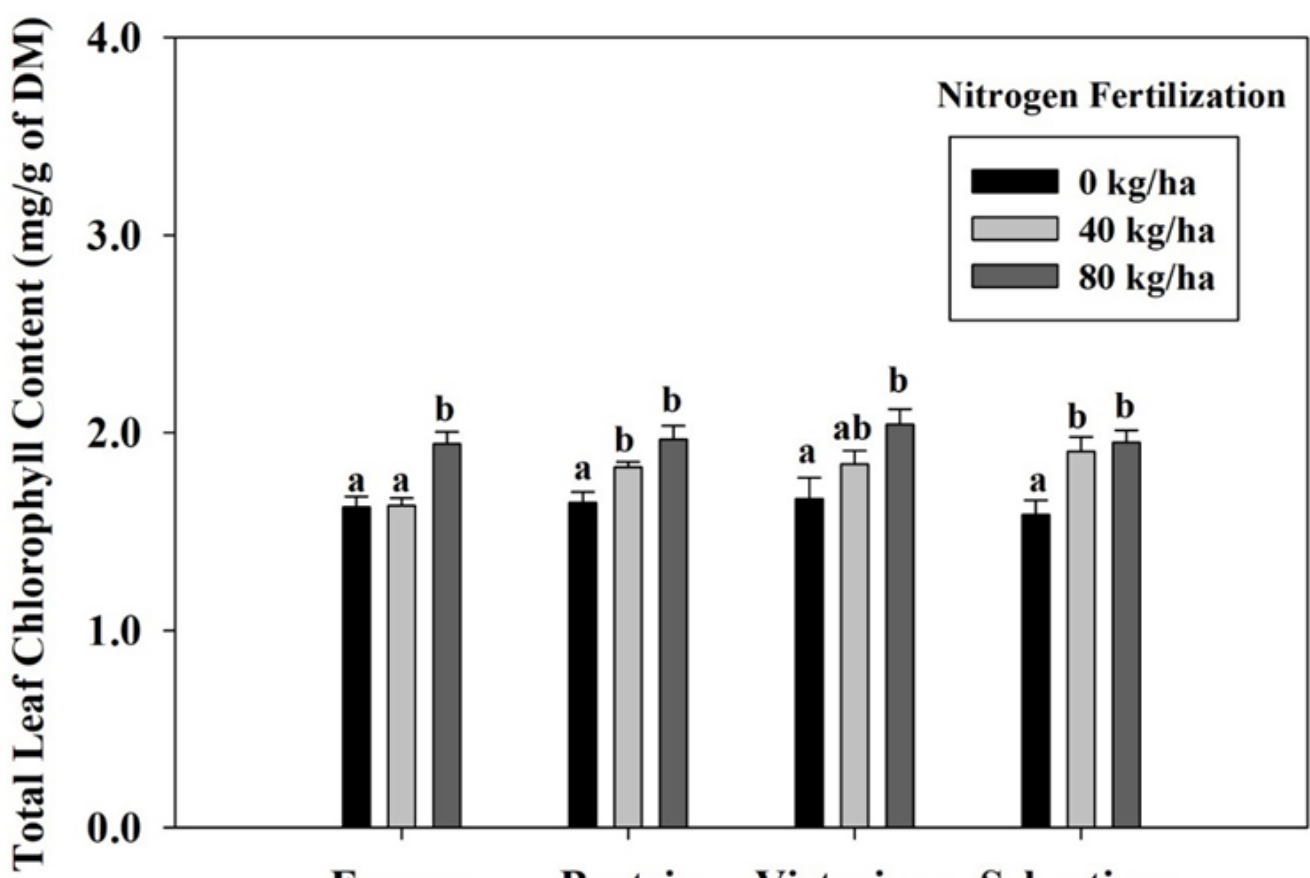

\section{Eunova Beatrix Victoriana Sebastiana}

Figure-6. Chlorophyll content (mg/g of DM) of leaf samples at 110 DAS of the barley cultivars Beatrix, Eunova, Sebastiana and Victoriana fertilized with different nitrogen levels $(\mathrm{o} \mathrm{kg} / \mathrm{ha}=$ black vertical bar; $40 \mathrm{~kg} / \mathrm{ha}=$ gray vertical bar; $80 \mathrm{~kg} / \mathrm{ha}=\mathrm{dark}$ gray vertical bar). Means $\pm \mathrm{SE}$ ( $\mathrm{n}=8$ repetitions) followed by different letters indicate significant differences between treatments within the cultivar (ANOVA, $p \leq$ $0.05)$ by Duncan Test.

\begin{tabular}{|c|c|c|c|}
\hline $\boldsymbol{R}^{2}$ & & after $s$ & \\
\hline Parameters & 75 & 85 & 110 \\
\hline Fluorescence indices & \multicolumn{3}{|c|}{ Grain yield (dt/ha) } \\
\hline \multicolumn{4}{|l|}{ Chlorophyll } \\
\hline Chl Index & 0.04 & 0.09 & $0.43^{*}$ \\
\hline SFR_R & 0.28 & $0.55^{*}$ & 0.21 \\
\hline $\mathrm{F} 730 / \mathrm{F} 690$ & $0.53^{*}$ & $0.53^{*}$ & 0.23 \\
\hline \multicolumn{4}{|l|}{ Nitrogen } \\
\hline NBI & 0.05 & 0.07 & 0.28 \\
\hline NBI_R & 0.24 & 0.18 & 0.03 \\
\hline \multicolumn{4}{|l|}{ Flavonol } \\
\hline FlavDx & 0.00 & 0.02 & 0.07 \\
\hline FlavMx & 0.15 & 0.01 & 0.01 \\
\hline Chlorophyll content (mg/g of DM) & & & $0.70^{*}$ \\
\hline
\end{tabular}

\section{DISCUSSION}

In this study, the effect of different nitrogen fertilization levels was reflected in leaf chlorophyll content and in grain yield values, as dosage increments were responsible for higher chlorophyll content and productivity. This response of crop production to $\mathrm{N}$ supply is in accordance with other studies, furthermore proving the importance of the nutrient as a major constituent of the chlorophyll molecule, whose supply can trigger an accumulation of the photosynthetic pigment in plants, thereby influencing final yield [33-36].

Chl_Index, SFR_R and F730/F690 are chlorophyll fluorescence indices considered as indicators of leaf chlorophyll content status. The recorded chlorophyll fluorescence signals expressed by these indices are all induced by incidence of light excitation in the $\mathrm{R}$ spectral region $[15,16,22,37]$. This incident light is transmitted to the mesophyll of the leaf, where the chlorophyll molecules are present at most [1]. Nitrogen is assimilated by plants 
and integrates the chlorophyll molecules, so that the content of this leaf pigment is strongly related to plant nitrogen status. In this study, all evaluated $\mathrm{FRF} / \mathrm{RF}$ indices yielded higher values with increased $\mathrm{N}$ dosages. Comparing these results with the total chlorophyll content at 110 DAS, those indices seem to provide a valid nondestructive prediction of plant chlorophyll status based on the $\mathrm{N}$ fertilization levels already established on 75 DAS. However, the differentiation between the barley cultivars, possibly due their similar growth and developing habit. On the other hand, this feature can also be positively scored, since these indices may be a useful instrument to estimate leaf chlorophyll status on any barley cultivar. A similar tendency was also found by Mauromicale, et al. [38], who studied chlorophyll fluorescence and chlorophyll content in field grown potato (Solanum tuberosum L.) as affected by nitrogen supply, genotype and plant age, establishing a positive linear correlation between nitrogen supply, chlorophyll fluorescence signals and chlorophyll content. Schächtl, et al. [14], employing a laser induced chlorophyll fluorescence sensor for detecting $\mathrm{N}$ status on wheat canopies, were also able to show a clear differentiation between $\mathrm{N}$ treatments as early as the beginning of stem elongation (BBCH3O).

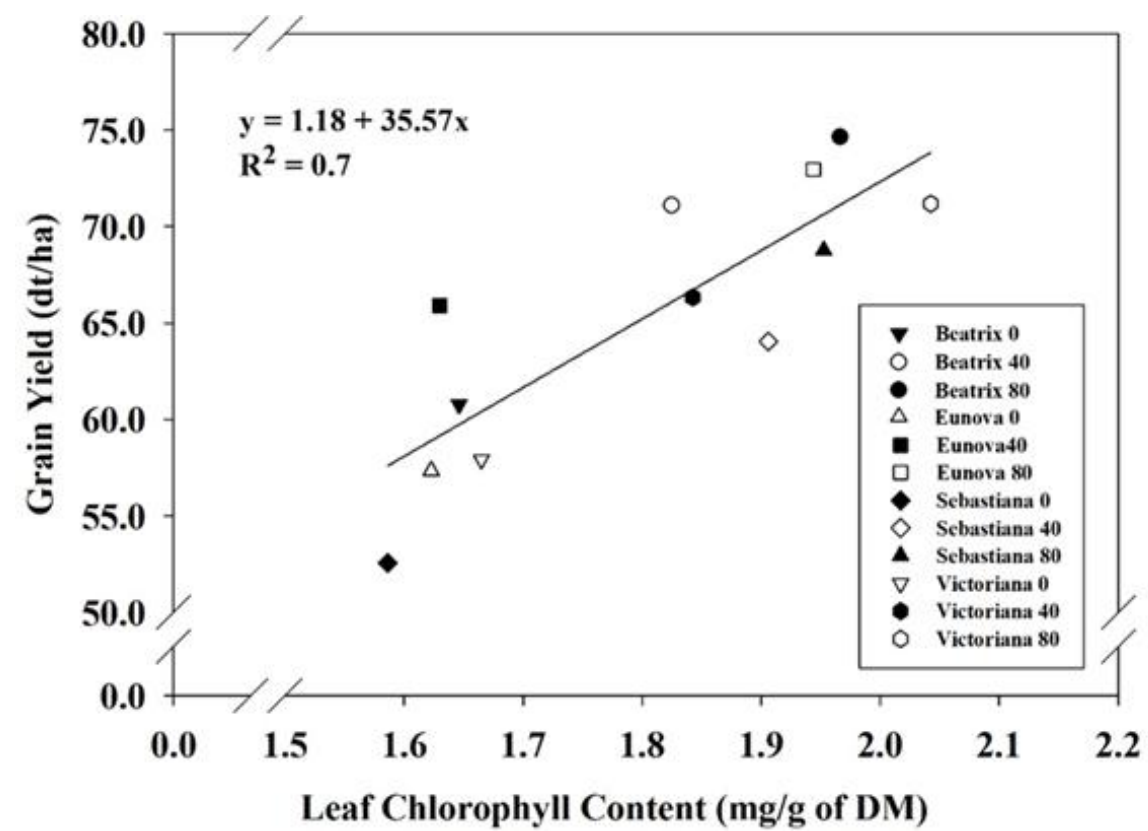

Figure-7. Coefficient of determination between chlorophyll content (mg/g of DM) at 110 DAS (days after sowing) (BBCH $59-61)$ and grain yield (dt/ha) at 142 DAS (BBCH 99) of four barley cultivars fertilized with different nitrogen (N) doses. Data are means $\pm \mathrm{SE}$ of 8 repetitions. Regression line obtained from coefficient of determination $(p \leq 0.05)$.

Additionally, flavonol indices were tested as indicators of plant nitrogen balance. Flavonoids are a large family of polyphenolic compounds found in plant tissues, the main group being the flavonols, that can increase in leaves in response to nitrogen stress [39]. Although Flav_Dx and Flav_Mx increased during the course of the vegetative and pre-generative stages of barley, no significant differences between different fertilization levels were seen. This was further proven by a weak coefficient of determination between those indices and final yield, suggesting that they are not completely suitable to be used as springboard to take decisions on crop nitrogen fertilization.

Abdallah, et al. [36] reviewed the utilization of ChlF for crop nitrogen status, whereby they compared variable chlorophyll fluorescence (Pulse-Amplitude-Modulation technique - PAM) and chlorophyll fluorescence sensing methods (the same as employed in the present study) for the estimation of concentrations of leaf metabolite compounds in plants, i.e. leaf chlorophyll and flavonoids. The authors emphasized that fluorescence ratios $(\mathrm{RF} / \mathrm{FRF}$ and FRF_UV/FRF_R), estimating the content of chlorophyll and flavonoids, can also be an indicator of plant $\mathrm{N}$ status (NBI). In our study, nitrogen balance indices (NBI and NBI_R) displayed similar tendencies compared to Chl 
indices, where plots without receiving any nitrogen fertilization expressed lowest indices values for plant nitrogen balance.

Similar curve tendencies were observed for all evaluated fluorescence indices irrespectively of the employed sensor. Fluorescence-based approaches could substantially screen the effect of nitrogen fertilization reflected by higher chlorophyll (F730/F690, Chl_Index and SFR_R) and nitrogen balance (NBI and NBI_R) indices at plots that received the higher fertilizer dosage - a pattern, subsequently, displayed on quantitative chlorophyll content and final grain yield. Thus, this assertion was discernible for those fluorescence indices, though performing low to moderate final yield predictions in some specific measuring events. Flavonol indices, in turn, were less precise in this prediction model, though a tendency could be observed in some stages, when higher Flav_Dx and Flav_Mx values figured on non-fertilized plots. In a similar way, the four cultivars did not ascertain a reliable prediction model, once leaf chlorophyll content and grain yield were not statistically distinct between cultivars, differently from the fluorescence indices. A predominately non-significant interaction between both treatments during the evaluation stages could explain the lower cultivar effect on the final outcomes. In addition, leaf chlorophyll content presented a strong correlation with the final grain yield. However, fluorescence-based indices presented here are initially rather wary and they should in principle be considered in studies to distinguish the effect of nitrogen fertilization levels. Moreover, further studies might concentrate on more cultivars, field conditions, cultivation years, as well as fluorescence models, where other adapted indices should also be taken into account.

\section{ACKNOWLEDGEMENTS}

A special thanks to PD Dr. Mauricio Hunsche, who worked as advisior during the conduction of the experiment and data interpretation, and the technical staff of the Department of Horticultural Science from the University of Bonn for the laboratory analysis.

\section{REFERENCES}

[1] N. Tremblay, Z. Wang, and Z. G. Cerovic, "Sensing crop nitrogen status with fluorescence indicators: A review," Agronomy for Sustainable Development, vol. 32, pp. 45 1-464, 2012.Available at: https://doi:10.1007/s 13593-011-0041-1.

[2] U. Sonnewald, Stoffwechselphysiologie. In: Kradereit J.W., Körner C., Kost B. and Sonnewald U. (Eds). Lehrbuch der Pflanzenwissenschaften, 37th ed. vol. 19. Berlin, Heidelberg, Germany: Springer-Verlag, 2014.

[3] H.-M. Lam, K. Coschigano, I. Oliveira, R. Melo-Oliveira, and G. Coruzzi, "The molecular-genetics of nitrogen assimilation into amino acids in higher plants," Annual Review of Plant Biology, vol. 47, pp. 569-593, 1996.

[4] J. A. Silva and R. Uchida, Biological nitrogen fixation. In: J.A.Silva and R. Uchida (Eds). Plant Nutrient Management in Hawaii's Soils, Approaches for Tropical and Subtropical Agriculture. Manoa: College of Tropical Agriculture and Human Resources, 2000.

[5] L. Taiz and E. Zeiger, Photosynthesis: Physiological and ecological considerations. In: L.Taiz and E. Zeiger (Eds). Plant physiology, 4th ed. Sunderland, MA, USA: Sinauer Associates, 2006.

[6] D. Zhao, K. R. Reddy, V. G. Kakani, and V. R. Reddy, "Nitrogen deficiency effects on plant growth, leaf photosynthesis, and hyperspectral reflectance properties of sorghum," European Journal of Agronomy, vol. 22, pp. 391403,, 2005.Available at: 10.1016/j.eja.2004.06.005

[7] J. W. Radin, L. L. Parker, and G. Guinn, "Water relations of cotton plants under nitrogen deficiency," Crop Science, vol. 2, pp. 1066-1070, 1982.

[8] S. Palmer, D. M. Berridge, A. McDonald, and W. Davies, "Control of leaf expansion in sunflower (Helianthus annuus L.) by nitrogen nutrition," Journal of Experimental Botany, vol. 47, pp. 359-368, 1996. 
[9] I. Dodd, R. Munns, and J. Passioura, "Does shoot water status limit leaf expansion of nitrogen-deprived barley?," Journal of Experimental Botany, vol. 53, pp. 1765-1770, 2002.Available at: https://doi.org/10.1093/jxb/erfo30.

[10] J. A. Lamb, F. G. Fernandez, and D. E. Kaiser, Understanding nitrogen in soils - Revised. Saint Paul, Minnesota, USA: University of Minnesota Extention, 2014.

[11] K. Goulding, S. Jarvis, and A. Whitmore, "Optimizing nutrient management for farm systems," Philosophical Transactions of the Royal Society B: Biological Sciences, vol. 363, pp. 667-680, 2008.

[12] J. M. Briantais, C. Vernotte, G. H. Krause, and E. Weis, Chlorophyll a fluorescence of higher plants: Chloroplasts and leaves. In: J. A. Govindjee, and D. C. Fork (Eds), Light Emission by Plants and Bacteria. Orlando, FL, USA: Academic Press, 1986.

[13] G. Krause and E. Weis, "Chlorophyll fluorescence and photosynthesis: The basics," Annual Review of Plant Biology, vol. 42, pp. 313-349, 1991.

[14] J. Schächtl, G. Huber, F.-X. Maidl, E. Sticksel, J. Schulz, and P. Haschberger, "Laser-Induced chlorophyll fluorescence measurements for detecting the nitrogen status of wheat (Triticum aestivum L.) canopies," Precision Agriculture, vol. 6, pp. 143-156, 2005.

[15] N. B. Ghozlen, Z. G. Cerovic, C. Germain, S. Toutain, and G. Latouche, "Non-destructive optical monitoring of grape maturation by proximal sensing," Sensors, vol. 10, pp. 10040-10068, 2010.

[16] Z. G. Cerovic, G. Masdoumier, N. B. Ghozlen, and G. Latouche, "A new optical leaf-clip meter for simultaneous nondestructive assessment of leaf chlorophyll and epidermal flavonoids," Physiologia Plantarum, vol. 146, pp. 251-260, 2012.

[17] G. Agati, F. Fusi, P. Mazzinghi, and M. L. di Paola, "A simple approach to the evaluation of the reabsorption of chlorophyll fluorescence spectra in intact leaves," Journal of Photochemistry and Photobiology B: Biology, vol. 17, pp. 163171, 1993.Available at: https://doi.org/10.1016/1011-1344(93)80009-x.

[18] H. K. Lichtenthaler and U. Rinderle, "The role of chlorophyll fluorescence in the detection of stress conditions in plants," CRC Critical Reviews in Analytical Chemistry, vol. 19, pp. S29-S85, 1988.Available at: $10.1080 / 15476510.1988 .10401466$

[19] C. Buschmann, G. Langsdorf, and H. Lichtenthaler, "Imaging of the blue, green, and red fluorescence emission of plants: An overview," Photosynthetica, vol. 38, pp. 483-491, 2000.Available at: https://doi.org/10.1023/a:1012440903014.

[20] P. Campbell, E. Middleton, J. McMurtrey, L. Corp, and E. Chappelle, "Assessment of vegetation stress using reflectance or fluorescence measurements," Journal of Environmental Quality, vol. 36, pp. 832-845, 2007.Available at: https://doi.org/10.2134/jeq2005.0396.

[21] C. Buschmann, "Variability and application of the chlorophyll fluorescence emission ratio red/far-red of leaves," Photosynthesis Research, vol. 92, pp. 261-271, 2007.Available at: https://doi.org/10.1007/s11120-007-9187-8.

[22] U. Schmidhalter, F. X. Maidl, H. Heuwinkel, M. Demmel, H. Auernhammer, P. Noack, and M. Rothmund, Precision farming - adaptation of land use management to small scale heterogeneity. In: Schröder, P., Pfadenhauer, J., Munch, J.C. (Eds.), Perspectives for agroecosystem management. Elsevier B.V, 2008.

[23] K. Yu, G. Leufen, M. Hunsche, G. Noga, X. Chen, and G. Bareth, "Investigation of leaf diseases and estimation of chlorophyll concentration in seven barley varieties using fluorescence and hyperspectral indices," Remote Sensing, vol. 6, pp. 64-86, 2013.Available at: https//doi:10.3390/rs6010064.

[24] M. Kalaji and P. Guo, "Chlorophyll fluorescence: A useful tool in barley plant breeding programs," Photochemistry Research Progress, vol. 29, pp. 439-463, 2008.

[25] C. Jedmowski and W. Brüggemann, "Imaging of fast chlorophyll fluorescence induction curve (OJIP) parameters, applied in a screening study with wild barley (Hordeum spontaneum) genotypes under heat stress," Journal of 
Photochemistry and Photobiology B: Biology, vol. 151, pp. 153-160, 2015.Available at: https://doi.org/10.1016/j.jphotobiol.2015.07.020.

[26] A. Witzenberger, B. VAN DEN, and H. Hack, "Explanations of the BBCH decimal code for the development stages of the grain - with pictures," Gesunde Pflanzen, vol. 41, pp. 384-388, 1989.

[27] P. D. Lancashire, H. Bleiholder, T. v. d. Boom, P. Langelüddeke, R. Stauss, E. Weber, and A. Witzenberger, "A uniform decimal code for growth stages of crops and weeds," Annals of applied Biology, vol. 119, pp. 561-601, 1991.Available at: https://doi.org/10.1111/j.1744-7348.1991.tb04895.x.

[28] G. Leufen, G. Noga, and M. Hunsche, "Proximal sensing of plant-pathogen interactions in spring barley with three fluorescence techniques," Sensors, vol. 14, pp. 11135-11152, 2014.Available at: https://doi.org/10.3390/s140611135.

[29] G. Leufen, G. Noga, and M. Hunsche, "Physiological response of sugar beet (Betavulgaris) genotypes to a temporary water deficit, as evaluated with a multiparameter fluorescence sensor," Acta Physiologiae Plantarum, vol. 35, pp. 17631774, 2013.Available at: https://doi.org/10.1007/s11738-012-1213-6.

[30] K. Bürling, M. Hunsche, and G. Noga, "Use of blue-green and chlorophyll fluorescence measurements for differentiation between nitrogen deficiency and pathogen infection in winter wheat," Journal of Plant Physiology, vol. 168, pp. 1641-1648, 2011 .Available at: https://doi.org/10.1016/j.jplph.2011.03.016.

[31] M. Holden, "Chlorophylls," Chemistry and Biochemistry of Plant Pigments, vol. 2, pp. 2-37, 1976.

[32] A. Strobl and R. Türk, "Investigations on the chlorophyll content of somesubalpine lichens," Phyton (Horn, Austria), vol. 30, pp. 247-264, 1990.

[33] C. Bredemeier and U. Schmidhalter, "Laser-induced chlorophyll fluorescence sensing to determine biomass and nitrogen uptake of winter wheat under controlled environment and field conditions. In: Stafford J. (Ed.)," in Precision Agriculture: Papers from the 5th European Conference on Precision Agriculture, Uppsala. Wageningen: Wageningen Academic Publishers, 2005, pp. 273-280.

[34] S. Güler, "Effects of nitrogen on yield and chlorophyll of potato (Solanum tuberosum L.) cultivars," Bangladesh Journal of Botany, vol. 38, pp. 163-169, 2009.Available at: https://doi.org/10.3329/bjb.v38i2.5 141.

[35] A. Alazmani, "Evaluation of yield and yield components of barley varieties to nitrogen," The Intlernational Journal of Agriculture and Crop Sciences, vol. 8, pp. 52-54, 2015.

[36] F. Abdallah, W. Philippe, and J.-P. Goffart, "Use of chlorophyll fluorescence for the evaluation of crops nitrogen status. A review," Biotechnologie, Agronomie, Société et Environnement, vol. 20, pp. 83-93, 2016.

[37] A. A. Gitelson, C. Buschmann, and H. K. Lichtenthaler, "The chlorophyll fluorescence ratio F735/F700 as an accurate measure of the chlorophyll content in plants," Remote Sensing of Environment, vol. 69, pp. 296-302, 1999.Available at: https://doi.org/10.1016/s0034-4257(99)00023-1.

[38] G. Mauromicale, A. Ierna, and M. Marchese, "Chlorophyll fluorescence and chlorophyll content in field-grown potato as affected by nitrogen supply, genotype, and plant age," Photosynthetica, vol. 44, pp. 76-82, 2006.Available at: https://doi.org/10.1007/s11099-005-0161-4.

[39] A. Stewart, W. Chapman, G. Jenkins, I. Graham, T. Martin, and A. Crozier, "The effect of nitrogen and phosphorus deficiency on flavonol accumulation in plant tissues," Plant, Cell $\Xi^{2}$ Environment, vol. 24, pp. 1189-1197, 2001.Available at: https://doi.org/10.1046/j.1365-3040.2001.00768.x.

Online Science Publishing is not responsible or answerable for any loss, damage or liability, etc. caused in relation to/arising out of the use of the content. Any queries should be directed to the corresponding author of the article. 